\title{
Doxorubicin-Loaded Metal-Organic Framework Nanoparticles as Acid-Activatable Hydroxyl Radical Nanogenerators for Enhanced Chemo/Chemodynamic Synergistic Therapy
}

\author{
Honghui Li ${ }^{1,+}$, Ying Zhang ${ }^{1,+}$, Lingxia Liang ${ }^{1,2,+}$, Jiaxing Song ${ }^{3}$, Zixuan Wei ${ }^{1}$, Shuyue Yang ${ }^{1}$, Yunong Ma ${ }^{1}$, \\ Wei R. Chen ${ }^{4}$, Cuixia Lu ${ }^{1, *}$ and Liewei Wen ${ }^{2, *(1)}$ \\ 1 Medical College, Guangxi University, Nanning 530004, China; sailo1997@163.com (H.L.); \\ zhangy2313@163.com (Y.Z.); xiaotuliang1996@163.com (L.L.); qiangkunxuan@163.com (Z.W.); \\ 18654363051@163.com (S.Y.); mynnong@163.com (Y.M.) \\ 2 Zhuhai Precision Medical Center, Zhuhai People's Hospital (Zhuhai Hospital Affiliated with Jinan \\ University), Jinan University, Zhuhai 519000, China \\ 3 Guangdong Key Laboratory for Genome Stability \& Disease Prevention, Cancer Research Center, Department \\ of Pharmacology, Shenzhen University Health Science Center, Shenzhen 518000, China; kerphilo@163.com \\ 4 Stephenson School of Biomedical Engineering, Gallogly College of Engineering, University of Oklahoma, \\ Norman, OK 73019, USA; wei-r-chen@ou.edu \\ * Correspondence: lucuixia@gxu.edu.cn (C.L.); wenner1989@163.com (L.W.) \\ + These authors contributed equally to this work.
}

check for updates

Citation: Li, H.; Zhang, Y.; Liang, L.; Song, J.; Wei, Z.; Yang, S.; Ma, Y.;

Chen, W.R.; Lu, C.; Wen, L.

Doxorubicin-Loaded Metal-Organic Framework Nanoparticles as Acid-Activatable Hydroxyl Radical Nanogenerators for Enhanced Chemo/Chemodynamic Synergistic Therapy. Materials 2022, 15, 1096. https://doi.org/10.3390/ ma15031096

Academic Editors: Fabien Delpech, Alina Sionkowska and Mutlu Özcan

Received: 17 November 2021

Accepted: 26 January 2022

Published: 30 January 2022

Publisher's Note: MDPI stays neutral with regard to jurisdictional claims in published maps and institutional affiliations.

Copyright: (C) 2022 by the authors. Licensee MDPI, Basel, Switzerland. This article is an open access article distributed under the terms and conditions of the Creative Commons Attribution (CC BY) license (https:// creativecommons.org/licenses/by/ $4.0 /)$.

\begin{abstract}
Doxorubicin (DOX) is a widely used first-line antitumor agent; however, acquired drug resistance and side effects have become the main challenges to effective cancer therapy. Herein, DOX is loaded into iron-rich metal-organic framework/tannic acid (TA) nanocomplex to form a tumor-targeting and acid-activatable drug delivery system (MOF/TA-DOX, MTD). Under the acidic tumor microenvironment, MTD simultaneously releases DOX and ferrous ion $\left(\mathrm{Fe}^{2+}\right)$ accompanied by degradation. Apart from the chemotherapeutic effect, DOX elevates the intracellular $\mathrm{H}_{2} \mathrm{O}_{2}$ levels through cascade reactions, which will be beneficial to the Fenton reaction between the $\mathrm{Fe}^{2+}$ and $\mathrm{H}_{2} \mathrm{O}_{2}$, to persistently produce hydroxyl radicals $(\bullet \mathrm{OH})$. Thus, MTD efficiently mediates chemodynamic therapy (CDT) and remarkably enhances the sensitivity of chemotherapy. More encouragingly, the cancer cell killing efficiency of MTD is up to $\sim 86 \%$ even at the ultralow equivalent concentration of DOX $(2.26 \mu \mathrm{g} / \mathrm{mL})$, while the viability of normal cells remained $>88 \%$ at the same concentration of MTD. Taken together, MTD is expected to serve as drug-delivery nanoplatforms and $\bullet \mathrm{OH}$ nanogenerators for improving chemo/chemodynamic synergistic therapy and reducing the toxic side effects.
\end{abstract}

Keywords: doxorubicin; chemotherapy; metal-organic framework; hydroxyl radicals; chemodynamic therapy

\section{Introduction}

Cancer ranks as a leading cause of death in countries around the world, and the burden of cancer incidence and mortality is rapidly increasing worldwide. Chemotherapy is one important clinical procedure for cancer treatment [1]. However, multidrug resistance and side effects of anticancer drugs have become the major challenges that limit the successful outcome of this option $[2,3]$. Thus, exploring the method of reducing the strong side effects and the potential molecular mechanisms involved in drug resistance will contribute greatly to increasing the therapy efficiency $[4,5]$. As an anthracycline antitumor agent, DOX has good clinical efficacy in the treatment of a variety of tumors. DOX can be tightly bound to DNA by embedding between $\mathrm{G}-\mathrm{C}$ base pairs and destroying its spatial structure in the presence of a considerable concentration of drugs, thereby inhibiting the synthesis of DNA and DNA-dependent RNA, then inhibiting cell transcription and proliferation [6,7]. Despite the extensive and long-term clinical application of DOX, substantial hurdles remain to be 
addressed, including non-specific delivery, poor solubility, short half-life, evoked multidrug resistance, and other strong side effects. Nowadays, multifunctional nanoparticles have been developed to deliver antitumor drugs through active or passive targeting, such as liposomes and polymer micelles [8]. Nanoparticles-based therapies have gained attention and made gratifying progress in the battle for cancer treatment. As the first FDA-approved anticancer nanodrug, Doxil ${ }^{\circledR}$ (PEGylated liposomal formulation of doxorubicin) was approved for the clinical treatment of ovarian and metastatic breast cancer, as well as various forms of myeloma [9]. Since the success of Doxil in clinical trials, a myriad of studies has been conducted to transform R\&D efforts into commercially available products. Unexpectedly, the clinical data did not manifest that Doxil enhanced antitumor efficacy, compared with the upshot of free DOX [10,11]. There still exists an urgent medical demand to improve the efficacy or reduce the toxic side effects of DOX.

Recently, the activatable nanocarriers for drug delivery have attracted extensive attention because of their more specific drug-release property, which remarkably increases the effective concentration of drugs at tumor sites [12]. It is well known that the occurrence and development of malignant tumors result in the special tumor microenvironment (TME), such as hypoxia, low $\mathrm{pH}$, low catalase expression, etc. [13]. Therefore, the studies on activatable nanocarriers that respond to TME and intracellular signals can overcome crucial challenges in conventional nanodrug delivery systems, which will be helpful in enhancing the therapeutic efficacies and reducing the side effects [14]. In particular, the acidic $\mathrm{pH}$ of tumor extracellular and intracellular microenvironment is regarded as an appropriate internal trigger for the drug release in the tumor region and/or within the endosomes and lysosomes of tumor cells. Compared with the $\mathrm{pH}$ value of normal tissues ( $\mathrm{pH} 7.4)$, the extracellular $\mathrm{pH}$ value of tumor is between 6.0 and 7.2 [15], and the $\mathrm{pH}$ value of lysosomes and endosomes of tumor cells decreased to 4.0-5.0 [16]. Metal-organic framework (MOF) nanoparticles with unique physicochemical properties, such as tunable and porous structure, easy functionalization, and large surface areas, had been extensively used for drug delivery, catalysis, and imaging [17-19]. MOFs can be biodegradable due to the weak coordination bonds, which definitely permits a promising platform for drug delivery and stimuli-responsive release [19]. MIL-101(Fe)- $\mathrm{NH}_{2}$ nanoparticles have been found to have high drug loading efficiency and possess enhanced tumor cell uptake. Moreover, they have been shown to have a $\mathrm{pH}$-responsive release property [20]. In addition, it is worth noting that MIL-101(Fe)- $\mathrm{NH}_{2}$ nanoparticles mimicking enzymes are capable of catalyzing $\mathrm{H}_{2} \mathrm{O}_{2}$ in the tumor microenvironment, to generate hydroxyl radical $(\bullet \mathrm{OH})$ through Fenton reaction, and inducing tumor cell apoptosis, which is termed chemodynamic therapy (CDT) $[18,21]$. Unfortunately, the CDT efficacy is severely limited by $\mathrm{H}_{2} \mathrm{O}_{2}$ supply and iron metabolism in the tumor. Accordingly, it is a greatly necessary and important way to increase the production of $\bullet \mathrm{OH}$ by elevating the content of intracellular $\mathrm{H}_{2} \mathrm{O}_{2}$ level and increasing the catalyst iron ions amount in tumors.

Prior studies have shown that DOX elevates the intracellular $\mathrm{H}_{2} \mathrm{O}_{2}$ level through PARP and NADPH oxidase activation except inducing cell apoptosis through inhibition of topoisomerase II [22,23]. It is believed that DOX can enhance oxidative stress, which is expected to improve the MIL-101(Fe)- $\mathrm{NH}_{2}$ nanoparticles-initiated CDT efficacy by promoting the production of $\bullet \mathrm{OH}$. In this study, MIL-101(Fe)- $\mathrm{NH}_{2}$ nanoparticles were firstly chelated with a natural iron chelator tannic acid (TA) to form MOF/TA nanoparticles. Then, DOX was loaded into the inner cavities of MOF/TA nanoparticles with high efficiency, benefiting from its porous structure and large surface areas (Scheme 1a). The MOF/TADOX nanocomplexes (MTD) as a DOX delivery and acid-activatable release platform could release DOX in the acidic TME, accompanied by the degradation of MOF. Apart from the chemotherapeutic effect, DOX also elevated the content of intracellular $\mathrm{H}_{2} \mathrm{O}_{2}$ levels. Meanwhile, during the degradation process, ferric ion $\left(\mathrm{Fe}^{3+}\right)$ could be rapidly reduced to ferrous ion $\left(\mathrm{Fe}^{2+}\right)$ by TA. Consequently, the intracellular $\bullet \mathrm{OH}$ was rapidly and massively produced due to the considerably higher catalytic activity of $\mathrm{Fe}^{2+}$ and high content of $\mathrm{H}_{2} \mathrm{O}_{2}$ (Scheme 1b). The drug delivery and catalytic nanoplatform based on the iron-rich 
metal-organic framework/tannic acid (TA) nanocomplex was expected to furnish an alternative strategy for improving the efficacy of chemotherapy and reducing the side effects.
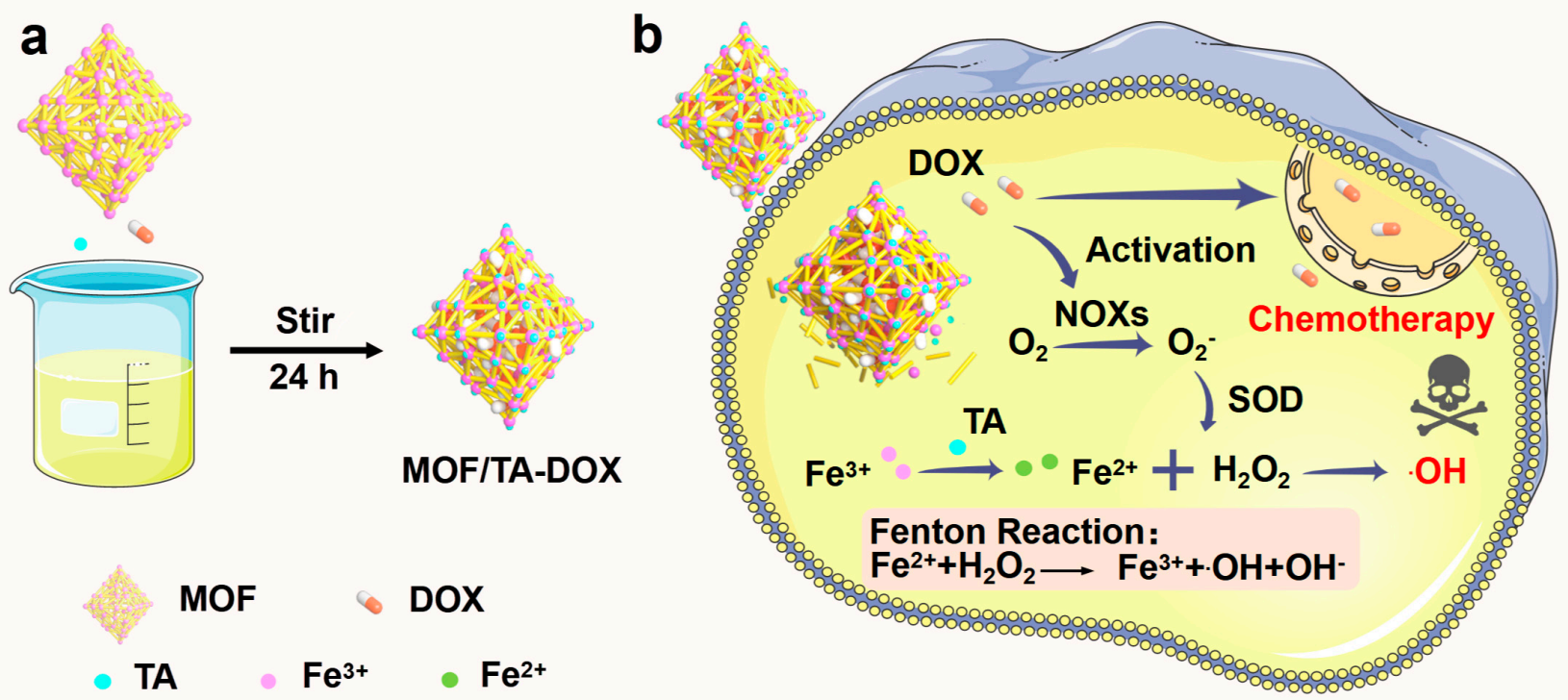

Scheme 1. Illustration of MTD as an acid-activatable nanodrugs enhancing tumor chemotherapy: (a) preparation of MTD and (b) mechanism of MTD enhancing tumor chemo/chemodynamic therapy.

\section{Materials and Methods}

\subsection{Chemicals and Materials}

Ferric chloride hexahydrate $\left(\mathrm{FeCl}_{3} \bullet 6 \mathrm{H}_{2} \mathrm{O}\right)$, amino terephthalic acid $\left(\mathrm{BDC}-\mathrm{NH}_{2}\right)$, and tannic acid (TA) were acquired from Macklin (Shanghai, China). ICG-NHS was purchased from Ruixibio (Xi'an city, China). Potassium bromide $(\mathrm{KBr})$ was purchased from Meryer (Shanghai, China). Methylene blue (MB) was purchased from Rhawn (Rhawn Co., Ltd., Shanghai, China). ROSGreen $\mathrm{H}_{2} \mathrm{O}_{2}$ probes were purchased from Shanghai Maokang Biotechnology, China. Finally, 2-(4-Amidinophenyl)-6-indolecarbamidine dihydrochloride (DAPI) was purchased from Beyotime Institute of Biotechnology (Shanghai, China).

\subsection{Characterization}

Morphological study of the MOF/TA was performed with transmission electron microscopy (TEM, JEM-1230, JEOL, Akishima, Japan) and scanning electron microscopy (SEM, Hitachi H-7593; Hitachi, Ltd., Tokyo, Japan). FTIR spectroscopy analyses of MOF, TA, and MOF/TA were conducted using an FT-IR spectrophotometer (Nicolet iS5, Thermo Fisher Scientific, Waltham, MA, USA). ESR spectra of different samples with DMPO were recorded on an ESR spectrometer (Bruker EMXnano, Bruker, Bremen, Germany). H\&E stains of mice tumors collected from different groups were imaged using an inverted fluorescence microscope (DM IRE2, Leica, Wetzlar, Germany). The hydrodynamic diameters of MOF/TA were determined by dynamic light scattering (DLS, Malvern Zetasizer Nano-ZS ZEN 3600, Malvern Instruments, Worcestershire, UK).

\subsection{Synthesis and Analysis of MTD Nanoparticles}

Typically, $1.8912 \mathrm{~g} \mathrm{FeCl}_{3} \bullet \mathrm{H}_{2} \mathrm{O}$ and $0.6339 \mathrm{~g}$ 2-aminoterephthalic acid were placed in a Teflon-lined autoclave, and $43 \mathrm{~mL}$ DMF was added. Next, the above solution was stirred at room temperature for $30 \mathrm{~min}$ until the chemical compounds were dissolved. Then, the Teflon-lined autoclave was put in an electric drying blower box subjected to solvothermal treatment at $180{ }^{\circ} \mathrm{C}$ for $24 \mathrm{~h}$. Through centrifugation $(10,500 \times \mathrm{g} \mathrm{rpm}, 10 \mathrm{~min})$ and washing with DMF three times, the nanoparticles were obtained. Then, the MOF nanoparticles were dried in a vacuum for further use. Afterward, $2 \mathrm{mg}$ MOF nanoparticles were dissolved in 
$2 \mathrm{~mL} \mathrm{ddH_{2 }}$ O, and $0.5 \mathrm{mg}$ TA was added; then, the MOF/TA nanoparticles were obtained by stirring the above mixture at room temperature for $12 \mathrm{~h}$. To obtain MTD, $5 \mathrm{mg}$ DOX was dissolved in $1 \mathrm{~mL}$ DMSO and dropwise added in MOF/TA solution (20 mg in $10 \mathrm{~mL}$ $\mathrm{ddH}_{2} \mathrm{O}$ ) and stirred at $37^{\circ} \mathrm{C}$ for $12 \mathrm{~h}$. The products were collected by centrifugation, washed three times with $\mathrm{ddH}_{2} \mathrm{O}$, and stored in $\mathrm{ddH}_{2} \mathrm{O}$.

To verify the loading content of DOX, the absorption spectra of MOF/TA, DOX, and MTD solution were measured by a microplate reader at $400-800 \mathrm{~nm}$. Different concentration $(0,5,25,50,80,100 \mu \mathrm{g} / \mathrm{mL})$ of DOX solution were prepared to make DOX standard curve.

$$
\text { Loading efficiency }(\%)=\text { Loaded DOX weight/Added DOX weight } \times 100
$$

Encapsulation efficiency $(\%)=$ Loaded DOX weight $/$ (Nanoparticle weight + Added DOX weight) $\times 100$

\subsection{Iron Release Analysis}

MOF/TA were dispersed in $5 \mathrm{~mL}$ acidic $(\mathrm{pH}=5.0)$ and neutral PBS $(\mathrm{pH}=7.4)$, and centrifugated at the indicated time point $(0,1,2,4,8,12,24 \mathrm{~h})$. The supernatant $(200 \mu \mathrm{L})$ was mixed with $200 \mu \mathrm{L}$ 1,10-phenanthroline monohydrate ( $0.1 \%)$, and the absorbance at $521 \mathrm{~nm}$ was measured using a microplate reader.

To analyze the concentration of iron released from MOF/TA, a standard curve of Fe iron concentration was obtained using different concentrations $(0,5,25,50,80,100 \mu \mathrm{g} / \mathrm{mL})$ of $\mathrm{FeCl}_{3}$ solution. Next, $200 \mu \mathrm{L}$ different $\mathrm{FeCl}_{3}$ solution was mixed with $200 \mu \mathrm{L}$ VC and $200 \mu \mathrm{L} 1,10$-phenanthroline monohydrate $(0.1 \%)$, and the absorbance at $521 \mathrm{~nm}$ was measured.

\subsection{Generation of Hydroxyl Radical $(\bullet \mathrm{OH})$}

Methylene-blue colorimetric method was used to analyze the generation of hydroxyl radical. The acidic PBS $(\mathrm{pH}=5.0)$ contained MB $(45 \mu \mathrm{g} / \mathrm{mL})$ was mixed with MOF/TA nanoparticles and $\mathrm{H}_{2} \mathrm{O}_{2}$. After $4 \mathrm{~h}$, the absorbance spectra were measured, and the absorbances at $665 \mathrm{~nm}$ were detected. The $\mathrm{MB}, \mathrm{MB}$ plus $\mathrm{H}_{2} \mathrm{O}_{2}$, and $\mathrm{MB}$ plus MOF/TA were set as the control. Generation of hydroxyl radical under neutral conditions was performed in PBS ( $\mathrm{pH}=7.4)$ using the same method.

\subsection{DOX Release from MTD}

The release of DOX was analyzed under acidic and neutral conditions. Briefly, $2 \mathrm{~mL}$ acidic $(\mathrm{pH}=5.0)$ or neutral $(\mathrm{pH}=7.4)$ PBS containing MTD was put in a dialysis bag (MWCO 3500) and immersed in $10 \mathrm{~mL}$ acidic PBS. The DOX concentration was detected with a microplate reader in $2 \mathrm{~mL}$ of acidic or neutral solution at a certain time point $(0,1,2$, $4,8,12,24 \mathrm{~h}$ ), and fresh $2 \mathrm{~mL}$ acidic or neutral PBS was used as the control.

\subsection{Uptake of MTD}

To study the internalization of MTD nanoparticles, the nanoparticles were labeled with ICG-NHS. $2 \times 10^{5}$ cells were cultured in $20 \mathrm{~mm}$ confocal dishes and grown overnight (12 h). ICG-labeled MTD nanoparticles were co-incubated with the cells for 1 or $4 \mathrm{~h}$ and washed with PBS three times. Finally, the cells were stained with DAPI for confocal microscope analysis.

\subsection{Cellular $\mathrm{H}_{2} \mathrm{O}_{2}$ Content}

To study the cellular $\mathrm{H}_{2} \mathrm{O}_{2}$ content of $4 \mathrm{~T} 1$ cells after MTD treatment, $2 \times 10^{5}$ cells in $20 \mathrm{~mm}$ confocal dishes were incubated for $4 \mathrm{~h}$ with PBS, MOF/TA, DOX, and MTD nanoparticles, respectively, and the cells were then washed with PBS three times and stained with ROS green $\mathrm{H}_{2} \mathrm{O}_{2}$ probes for confocal microscope analysis. 


\subsection{Fluorescence Imaging for Cellular Fe Ion Content and $\bullet \mathrm{OH}$}

Similarly, $2 \times 10^{5}$ cells were incubated for $4 \mathrm{~h}$ with PBS, MOF/TA, and MTD nanoparticles, respectively. After being washed with PBS three times, the cells were stained with PGSK probes for confocal microscope analysis to study the cellular Fe ion content of 4T1 cells after MTD treatment. After confocal analysis, the cells were collected for flow cytometry analysis.

Likewise, the cells were incubated with the indicated different treatments and stained with APF probes. The images were obtained by confocal microscope to study cellular $\bullet$ OH generation.

\subsection{Cell Viability}

The CCK-8 assay was applied to measure the toxicity of nanocomplexes in 4T1 cells. The cells $\left(5 \times 10^{3}\right.$ cells per well) were seeded in 96-well plates and grown overnight $(12 \mathrm{~h})$ and treated with MOF/TA, DOX, and MTD at 5, 10, 25, $50 \mu \mathrm{g} / \mathrm{mL}$. After treatment for $24 \mathrm{~h}$, CCK-8 solution ( $10 \mu \mathrm{L}$ per well) was added. After incubation for $2 \mathrm{~h}$, the absorbance at $450 \mathrm{~nm}$ was detected, and the relative cell viability was calculated.

\subsection{Animal Experiments}

All of the experiments were performed under protocols approved by the Animal Research Ethics Committee of Guangxi University. Balb/c nude female mice (4-5 weeks old) were purchased from Zhuhai BesTest Bio-Tech Co., Ltd. Afterward, 4T1 cells $\left(1 \times 10^{6}\right)$ were inoculated subcutaneously in the right hind thigh of mice. To study the distribution of nanoparticles, 4T1 tumor-bearing mice were injected with ICG and ICG-MTD via the tail vein. When the tumor volume reached about $100 \mathrm{~mm}^{3}$, the Balb/c nude mice were imaged at $1,2,4,8,12$, and $24 \mathrm{~h}$ after injection by the Living Image IVIS Spectrum (PerkinElmer).

When the tumor volume reached about $100 \mathrm{~mm}^{3}$, mice were randomly divided into four groups and treated with PBS, MOF/TA, and MTD $(10 \mathrm{mg} / \mathrm{kg})$, respectively. The nanoparticles were injected by the tail vein. During the treatment period, the body weight and tumor sizes (length and width) were measured every three days. The tumor volume was calculated by using the formula: $\mathrm{V}=\mathrm{L}$ (length) $\times \mathrm{W}$ (width) $\times \mathrm{W} / 2$. After treatment, mice were sacrificed, and the tumors and the organs were collected for H\&E analysis.

\subsection{Statistical Analysis}

Statistical analyses were conducted using Student's $t$-tests. Significance was calculated via unpaired two-tailed Student's $t$-test. $p$ value were calculated by $t$-test; ${ }^{*}$ and ${ }^{* *}$ indicated $p<0.05$ and $p<0.01$, respectively.

\section{Results}

\subsection{Preparation and Characterization of Nanodrugs}

The MOF nanoparticles (MIL-101(Fe)- $\mathrm{NH}_{2}$ ) were prepared according to a previously reported method [24]. The scanning electron microscope (SEM) images of the constructed MOF nanoparticles showed well dispersed and uniform nanoscale size, and the hydrated particle size of MOF was $\sim 174.6 \mathrm{~nm}$ (Figure 1a and insert). After stirring with TA, the FT-IR spectrum of MOF/TA showed the characteristic peak at $1200 \mathrm{~cm}^{-1}$ and $575 \mathrm{~cm}^{-1}$, which were attributed to the polyphenol -OH vibration of TA and Fe-O vibration of MOF, respectively. Meanwhile, the characteristic peak at $1200 \mathrm{~cm}^{-1}$ also showed weaker than TA due to the coordination of iron and polyphenol -OH groups (Figure 1b). Next, DOX was further stirred with MOF/TA, and the absorbance spectra showed that the characteristic absorption peak of DOX appeared in MTD (Figure 1c). According to the standard curve of DOX, the loading and encapsulation efficiencies were $82.61 \%$ and $4.52 \%$, respectively. In addition, the zeta potential of MTD changed from $+25.23 \mathrm{mV}$ to $-23.36 \mathrm{mV}$, suggesting the great stability of suspensions. These results indicated the successful preparation of the nanodrugs MTD. 
a

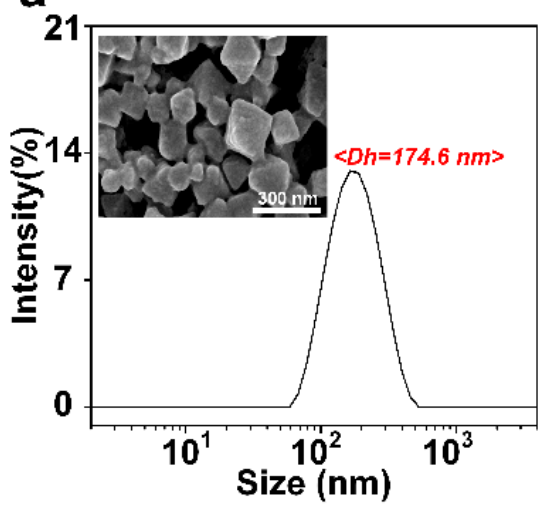

b

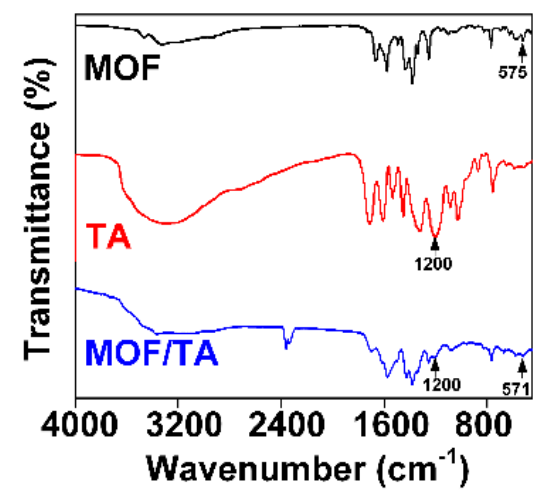

C

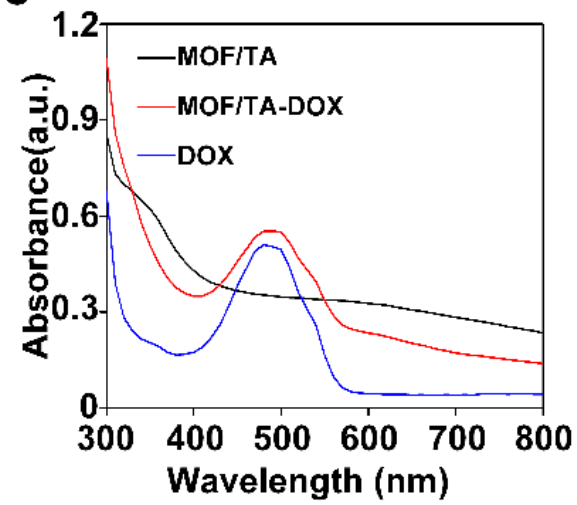

Figure 1. Preparation and synthesis of MTD: (a) the determination of particle size and morphology with SEM and DLS; (b) FTIR spectra; (c) UV-vis spectrum of nanoparticles.

\subsection{Analysis of Drug Release and $\bullet \mathrm{OH}$ Generation}

Nanoparticles, as drug delivery carriers, could be degraded and release drugs responsively by utilizing the characteristics of the tumor microenvironment, such as weak acidity and high GSH content $[25,26]$. Therefore, we firstly investigated the biodegradability of MOF/TA nanoparticles. TEM images showed that the MOF/TA nanoparticles displayed a regular square shape at $\mathrm{pH}=7.4$ and $\mathrm{pH}=5.0$ for $1 \mathrm{~h}$. However, under the acidic condition, the square shape of MOF/TA nanoparticles changed to round at $12 \mathrm{~h}$, while MOF/TA remained square shape under neutral PBS (Figure 2a), indicating the biodegradability of $\mathrm{MOF} / \mathrm{TA}$ nanoparticles under acidic conditions. Owing to this characteristic, iron ions could be released from the nanoparticles. Therefore, we next analyzed the release of iron ions by the O-phenanthroline spectrophotometry method. Under acidic conditions, the concentration of iron ions was $1.27624 \mathrm{mM}$ at $1 \mathrm{~h}$, while under neutral conditions, the number of iron ions was $0.00864 \mathrm{mM}$ at $1 \mathrm{~h}$ and remained a very low concentration at $24 \mathrm{~h}$, only $0.01811 \mathrm{mM}$ (Figure $2 \mathrm{~b}$ ). These results suggested the rapid release of iron ions from nanoparticles in a $\mathrm{pH}$-dependent manner, which will be beneficial for MOF/TA acting as Fenton reaction catalyzer to generate cytotoxic $\bullet \mathrm{OH}$ under acidic tumor microenvironment.

The concept of chemodynamic therapy was firstly proposed by Bu [27], which was dependent on transition metal elements, such as iron, manganese, and copper ions, to catalyze the $\bullet \mathrm{OH}$ production through the Fenton reaction. Due to $\mathrm{MB}$ oxidization by $\bullet \mathrm{OH}$ into colorless solution, an MB colorimetry assay was used to test the ability of MOF/TA nanoparticles to produce $\bullet \mathrm{OH}$. It was observed that the presence of $\mathrm{H}_{2} \mathrm{O}_{2}$ could reduce the absorption value of $\mathrm{MB}$ at $665 \mathrm{~nm}$, compared with the MOF/TA group. Notably, compared with the neutral condition, the absorption value of $\mathrm{MB}$ under acidic conditions was obviously decreased (Figure 2c,d). This resulted from efficient $\bullet \mathrm{OH}$ generation by Fenton reaction since many iron ions were rapidly released from MOF/TA nanoparticles under acidic conditions. Interestingly, MOF/TA alone could reduce the absorption value of $\mathrm{MB}$, which was related to the fact that $\mathrm{MB}$ is a kind of electronegative dye and can adsorb to positively charged nanoparticles [28].

Next, electron spin resonance spectroscopy (ESR) was used to verify whether MOF/TA nanoparticles have the ability to catalyze $\mathrm{H}_{2} \mathrm{O}_{2}$, to produce $\bullet \mathrm{OH}$. As shown in Figure 2e, the characteristic peak of $\bullet \mathrm{OH}$ could be observed in the presence of MOF/TA and $\mathrm{H}_{2} \mathrm{O}_{2}$, indicating the generation of $\bullet \mathrm{OH}$ catalyzed by MOF/TA. The drug release profiles of MTD were further evaluated in different $\mathrm{pH}$ conditions. The results showed that the cumulative release of DOX was in a time-dependent way. Compared with the neutral condition, the acidic condition facilitated the release of DOX from the nanoparticles (Figure 2f). 
a

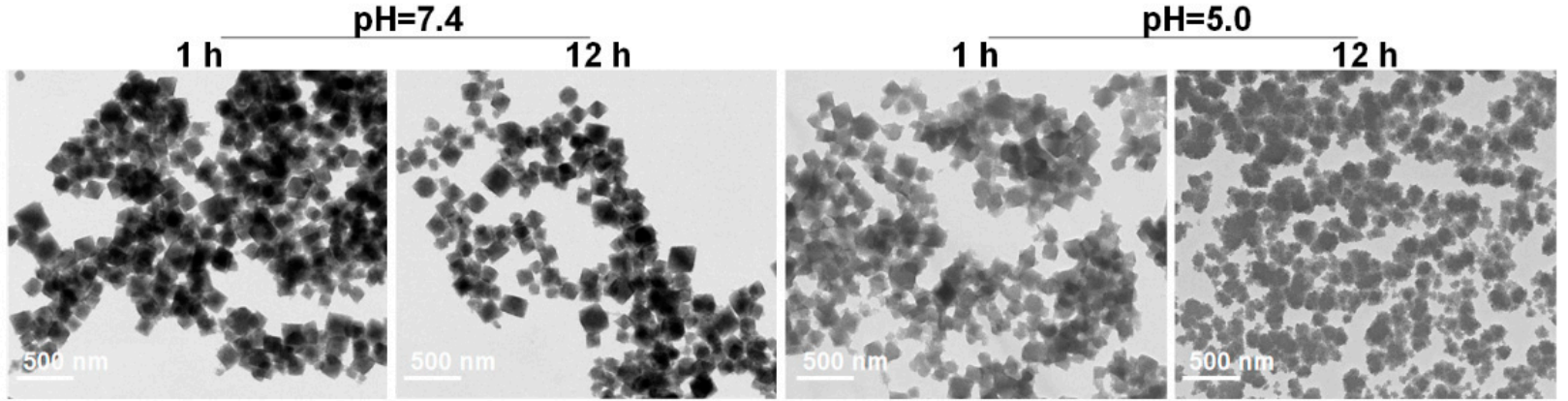

b

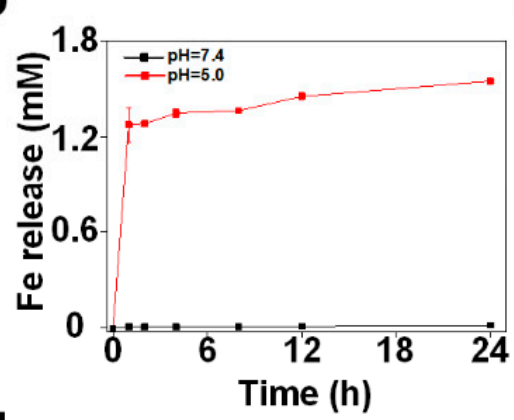

d

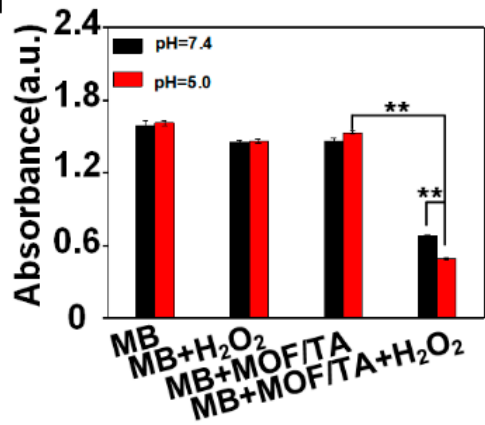

C

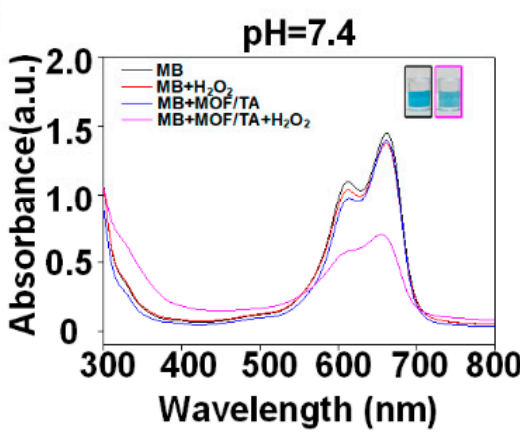

e

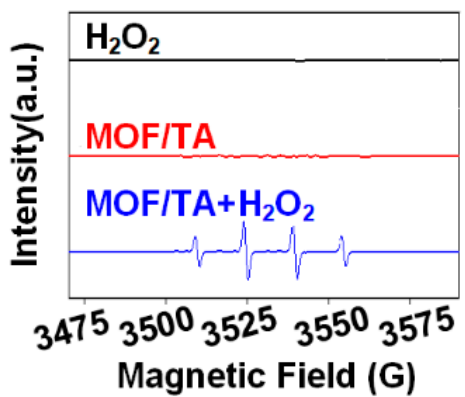

$\mathrm{pH}=\mathbf{5 . 0}$

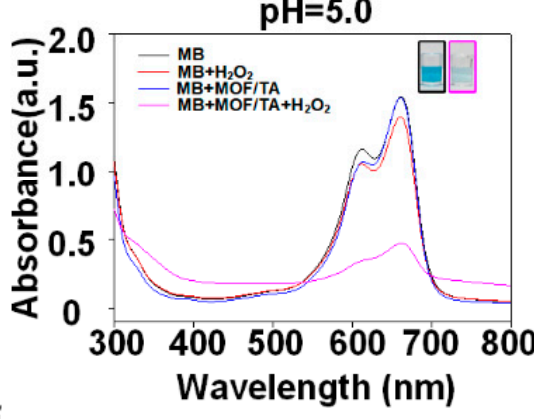

f

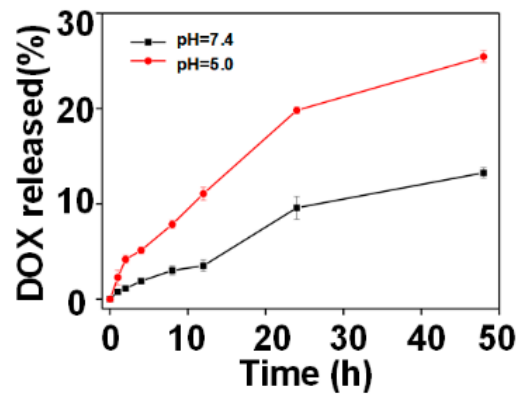

Figure 2. $\mathrm{pH}$-responsive property and $\bullet \mathrm{OH}$ generation of MOF/TA: (a) $\mathrm{pH}$-responsive biodegraded property of $\mathrm{MOF} / \mathrm{TA}$; (b) iron release behavior of MOF/TA; (c) MB absorbance spectrum under acidic and neutral conditions after the different treatments; (d) MB absorbance at $665 \mathrm{~nm}$ under acidic and neutral conditions after different treatments; (e) ESR spectrum of different samples; (f) DOX release behavior of MTD. Data are represented as the arithmetic mean $\pm \mathrm{SD}$, and one-way ANOVA followed by Dunnett's test were performed for statistical analysis $(* * p<0.01)$.

\subsection{Detection of Intracellular $\bullet \mathrm{OH}$ and Cytotoxicity of the Nanodrugs}

To verify if MTD can be internalized by tumor cells and exert chemotherapeutic effect by increasing the $\mathrm{H}_{2} \mathrm{O}_{2}$ levels, the $4 \mathrm{~T} 1$ cells were co-incubated with ICG-labeled MTD, and the images were obtained by CLSM analysis. As indicated in Figure 3a, strong green fluorescence was observed in the tumor cells after incubation for $4 \mathrm{~h}$, indicating that MTD could enter effectively into the cells. Notably, red fluorescence of DOX could be observed in both the cytoplasm and the nucleus. This result suggested that DOX released from MTD could enter the nucleus, which was consistent with a previous study. 
a

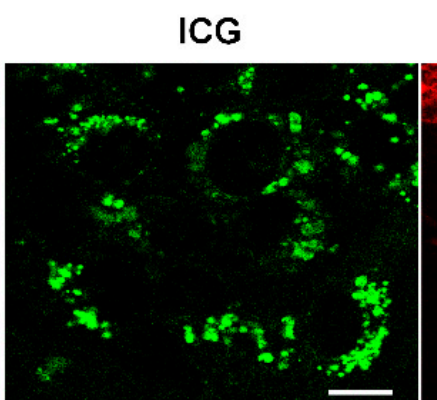

b

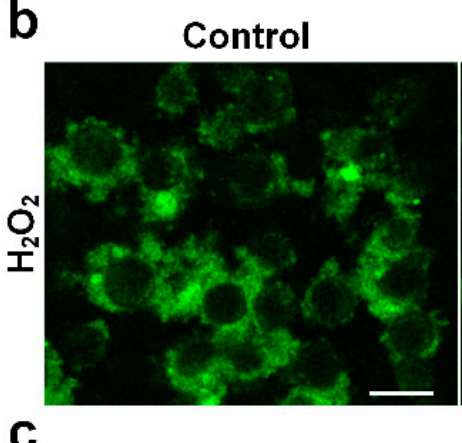

C

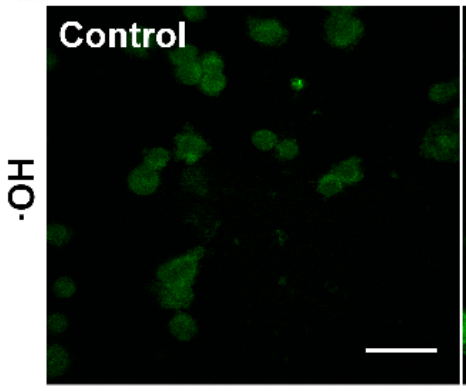

d

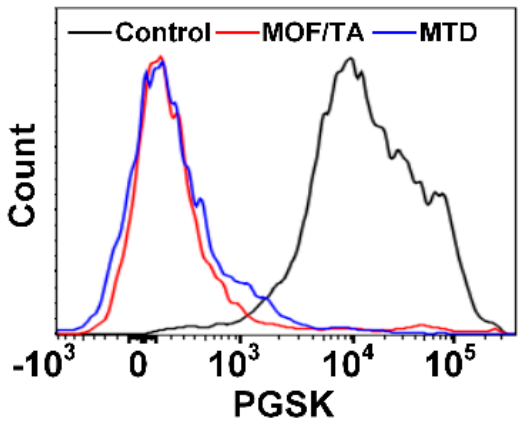

DOX

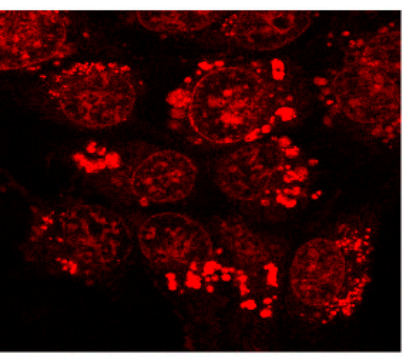

MOF/TA
DAPI

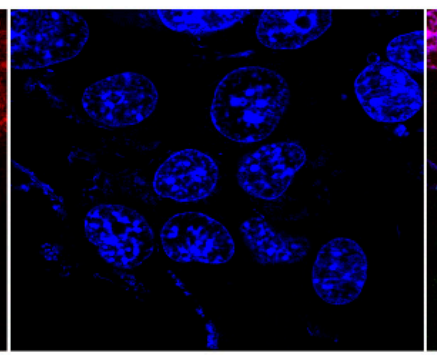

DOX
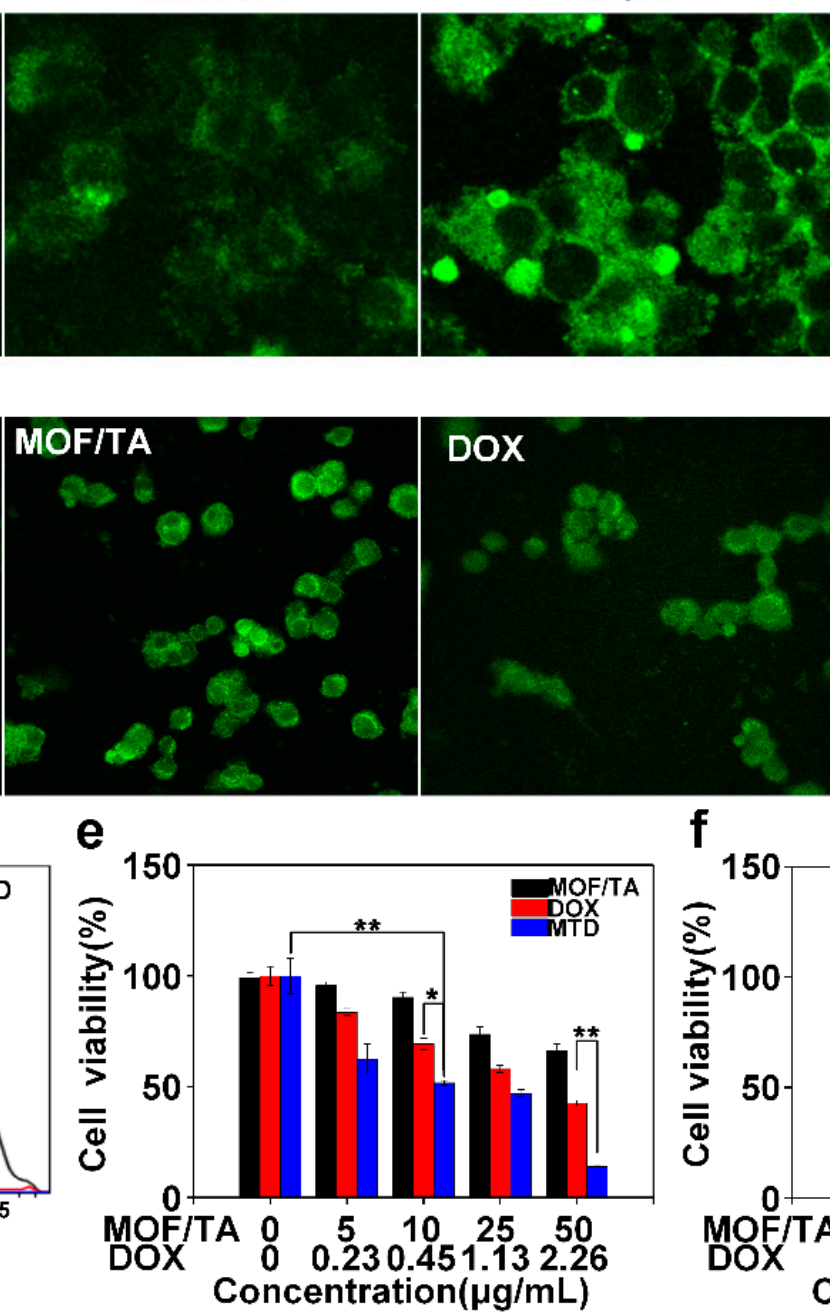
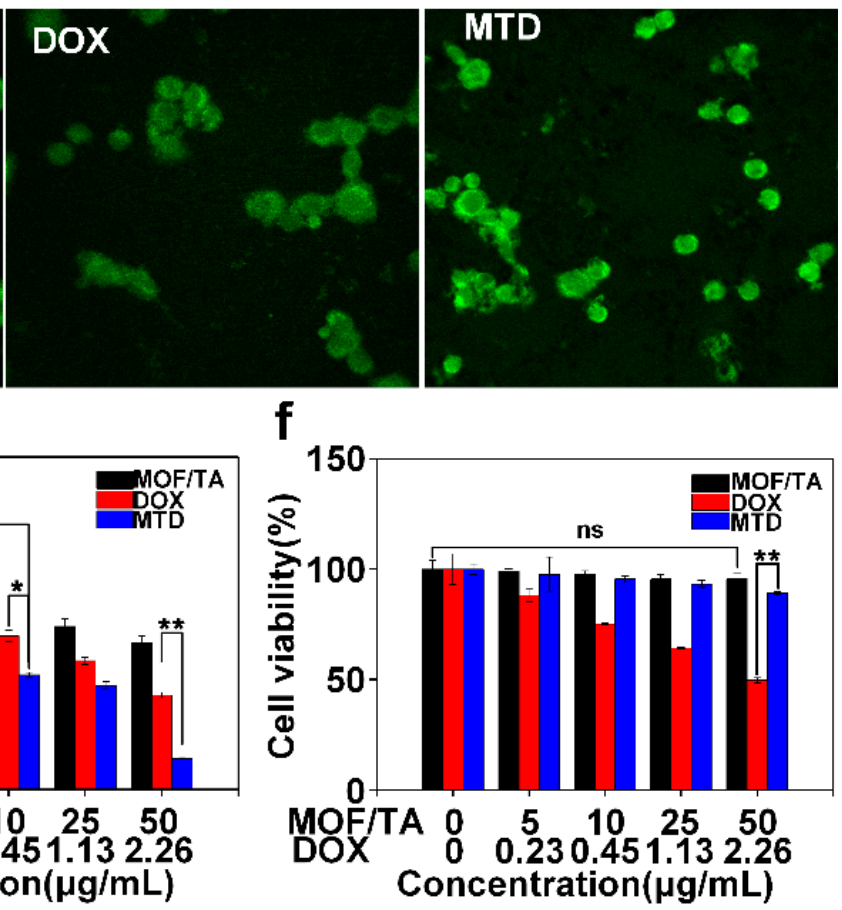

Figure 3. In vitro chemo/chemodynamic therapy effect: (a) CLSM images of MTD internalized behavior. Scale bar, $10 \mu \mathrm{m} ;(\mathbf{b})$ CLSM images of cellular $\mathrm{H}_{2} \mathrm{O}_{2}$ content after different treatments. Scale bar, $50 \mu \mathrm{m}$; (c) CLSM images of cellular $\bullet \mathrm{OH}$ content after different treatments. Scale bar, $20 \mu \mathrm{m}$; (d) flow cytometry analysis of cellular iron content after different treatments. The cell viability of (e) 4T1 and (f) MCF10A after different treatments were assessed with CCK8. Data are represented as the arithmetic mean $\pm \mathrm{SD}$, and one-way ANOVA followed by Dunnett's test were performed for statistical analysis $\left({ }^{*} p<0.05,{ }^{* *} p<0.01\right)$.

DOX can induce apoptosis as well as increase the content of $\mathrm{H}_{2} \mathrm{O}_{2}$ in cells [29]. Thus, a green fluorescence probe for $\mathrm{H}_{2} \mathrm{O}_{2}$ was used to detect the levels of intracellular $\mathrm{H}_{2} \mathrm{O}_{2}$ content by CLSM after the cells were incubated with the indicated treatments. The results showed that the green fluorescence intensity of DOX was stronger than that of the control 
group, indicating that the content of $\mathrm{H}_{2} \mathrm{O}_{2}$ in the cells was increased (Figure $3 \mathrm{~b}$ ). Compared with the control, treatment with MOF/TA obviously decreased the green fluorescence intensity. This was due to the consumption of $\mathrm{H}_{2} \mathrm{O}_{2}$ for the Fenton reaction catalyzed by MOF/TA. The presence of DOX could partly invert this inhibitory effect of MOF/TA. These results indicated that DOX could compensate for $\mathrm{H}_{2} \mathrm{O}_{2}$ consumption by MOF/TA to elevate the substrate of Fenton reaction and promote the formation of $\bullet \mathrm{OH}$, improving the sensitivity of chemotherapy.

Considering that MTD could increase the intracellular iron ions that catalyzed the formation of $\bullet \mathrm{OH}$ from $\mathrm{H}_{2} \mathrm{O}_{2}$ in tumor cells, and the chemotherapeutic drugs DOX released from MTD could elevate the intracellular $\mathrm{H}_{2} \mathrm{O}_{2}$ content as the substrates for Fenton reaction, we speculated that a considerable amount of cytotoxic $\bullet \mathrm{OH}$ could be produced in cells after MTD treatment. To verify this, an APF probe was used to detect the generation of $\bullet \mathrm{OH}$. The images obtained by CLSM showed an increase in fluorescence intensity in cells after treatment with DOX, MOF/TA, and MTD groups (Figure 3c).

Next, the effect of MTD on intracellular iron content was evaluated in tumor cells. A heavy metal fluorescence quenching indicator PGSK was used to indicate the content of iron ions in cells. After treatment with MOF/TA and MTD, the fluorescence intensity of PGSK in cells was significantly quenched, compared with that in the control group (Figure 3d), indicating that there was a high content of ferrous ions in the cells. The high concentration of iron ions in cells, as the catalyst of Fenton reaction, could provide the premise for the conversion of $\mathrm{H}_{2} \mathrm{O}_{2}$ to $\bullet \mathrm{OH}$. Among them, the strongest fluorescence intensity could be observed in cells treated with MTD, indicating that MTD treatment could efficiently induce cellular $\bullet \mathrm{OH}$ generation. Therefore, it is believed that MTD nanoparticles act as the $\bullet \mathrm{OH}$ nanogenerators to effectively kill tumor cells, resulting from Fenton reaction between intracellular iron originated from MOF- and DOX-induced $\mathrm{H}_{2} \mathrm{O}_{2}$ generation. In order to evaluate the cytotoxic effect of MTD, cell viability was detected after the different treatments by a CCK8 kit according to the manufacturer's protocol. As indicated in Figure 3e, cell viability was $<53 \%$ after treatment with $10 \mu \mathrm{g} / \mathrm{mL}$ MTD (the equivalent concentration of DOX is as low as $\sim 0.45 \mu \mathrm{g} / \mathrm{mL}$ ), and the viabilities in cells treated with the same concentration of MOF/TA; DOX was still $>63 \%$, indicating the synergistic chemotherapeutic effect of MTD. More encouragingly, the cancer cell killing efficiency of MTD was up to $\sim 86 \%$, even at the ultralow equivalent concentration of DOX $(2.26 \mu \mathrm{g} / \mathrm{mL})$, while the viability of normal cells remained $>88 \%$ at the same concentration of MTD (Figure 3f).

\subsection{Selective Distribution of Nanodrugs in Tumor}

To test if the nanoparticles could be enriched in tumors, ICG- or ICG-labeled MTD were, respectively, injected intravenously to $4 \mathrm{~T} 1$ tumor-bearing mice. Fluorescence images were obtained by the Living Image IVIS spectrum at the specified time points after injection. Strong fluorescence within the tumor could be detected in both ICG- and ICG-MTD groups at $8 \mathrm{~h}$, indicating selective accumulation of the nanoparticles in the tumor. It should be noted that strong fluorescence could be observed only in the tumor after ICG-MTD treatment, but mice injected with ICG showed strong fluorescence intensity in both the tumor and other organs (Figure 4a,b). These results indicated that ICG-labeled MTD exhibited a good target for tumors, which is beneficial to improve the antitumor effect of chemotherapy. We next analyzed the distribution of MTD in mice by harvesting the major organs and tumors for ex vivo fluorescence imaging at $8 \mathrm{~h}$ post injection. Indeed, tumors from the ICG-labeled MTD treated groups showed strong fluorescence, in comparison with the tumors from the free ICG-treated mice (Figure 4c). This result indicates that MTD nanocomplexes have the properties of long-term circulation and tumor-specific accumulation. It could not be ignored that the highest fluorescence signal was observed in the intestine, which suggested the excretion pathway of MTD (Figure 4d). 
a

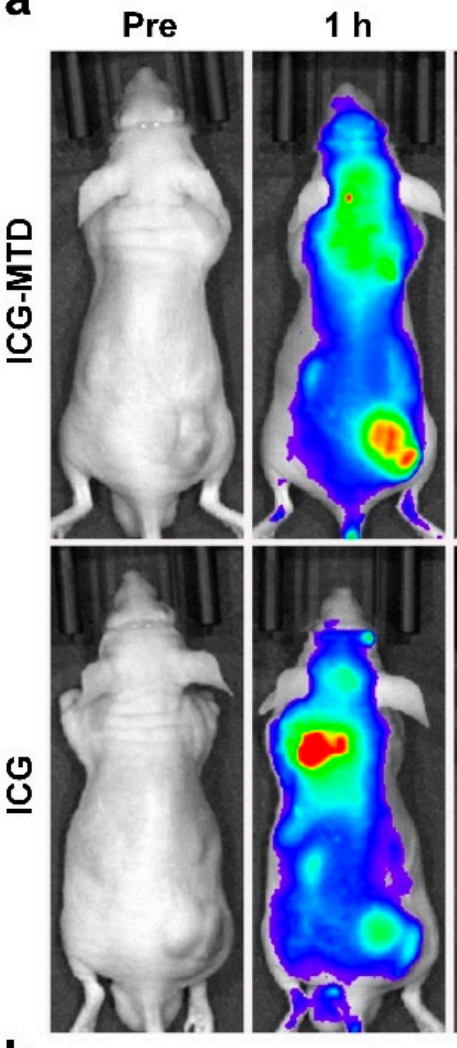

b

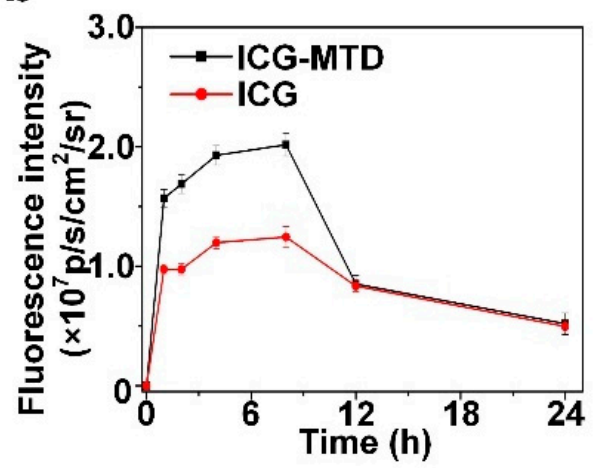

$2 \mathrm{~h}$
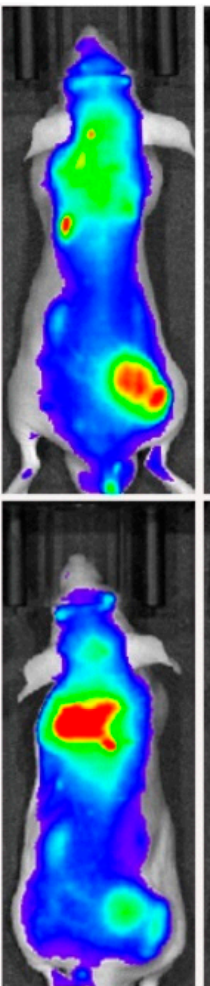

c
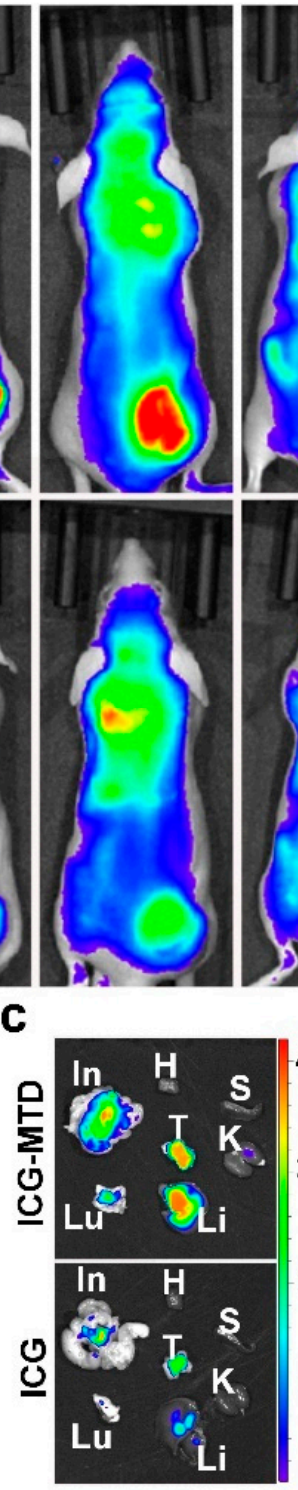

$8 \mathbf{h}$

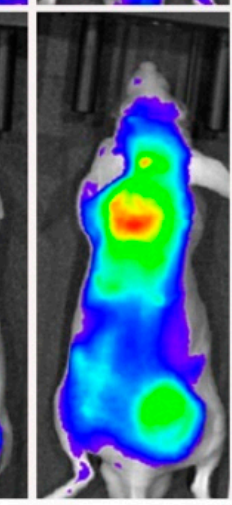

d

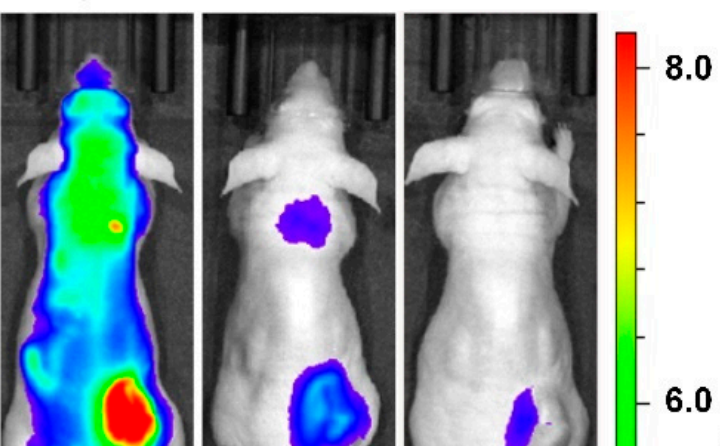

4.0

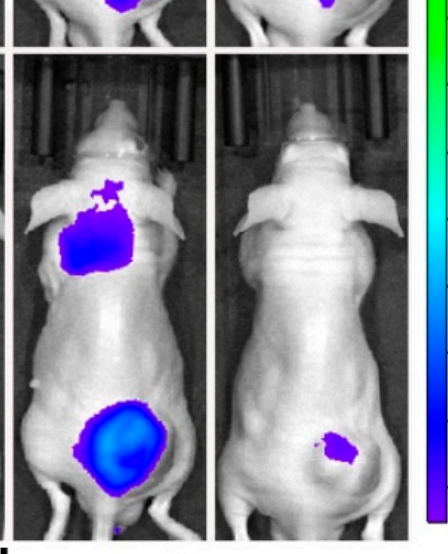

\section{$\frac{\frac{7}{0}}{\frac{\pi}{0}}$}

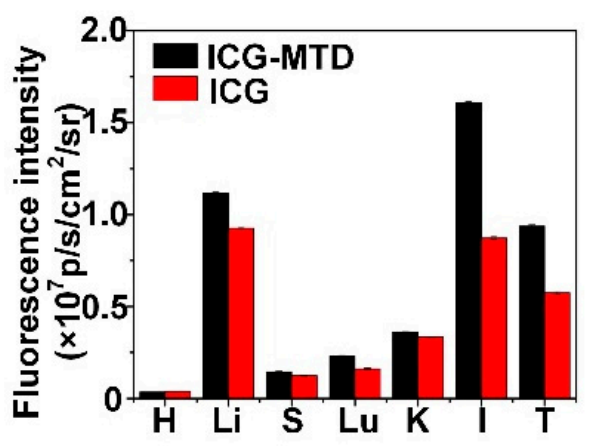

Figure 4. In vivo distribution of MTD: (a) fluorescence imaging of $4 \mathrm{~T} 1$ tumor-bearing mice after tail vein injection with ICG- or ICG-MTD; (b) MFI values of the ICG fluorescence following the treatment in (a); (c) ex vivo fluorescence images of major organs and tumors in mice at $8 \mathrm{~h}$ post injection; (d) the corresponding MFI analysis at $8 \mathrm{~h}$ post injection.

\subsection{Antitumor Effect of Nanodrugs In Vivo}

To evaluate the antitumor effects of nanoparticles in mice, mice bearing 4T1 tumors were divided into four different treatment groups: PBS, MOF/TA, DOX, and MTD. After injection, tumor growth and body weight of mice were monitored every three days. As shown in Figure 5a, the average tumor size in MOF/TA, DOX, and MTD groups was smaller than that of the control group, indicating their inhibition effects on tumor growth. Treatment with MTD showed the highest inhibitory rate of $93.728 \%$ on tumor growth, which was attributed to the synergistic chemotherapeutic effects of nanoparticles. Meanwhile, the body weights of mice in each treatment group did not show an obvious change (Figure $5 b$ ), indicating that the nanoparticles have good biological safety. In order to further study the killing effect of nanoparticles on the tumor, tumor tissues of each treatment group were collected after the treatment period, and H\&E was performed (Figure 5c). Obvious damage could be observed in tumor tissue from the mice treated with MTD. These results 
demonstrate that the MTD nanoparticles have good tumoricidal effects and biological safety through selectively targeting tumors and effectively inducing tumor damage.

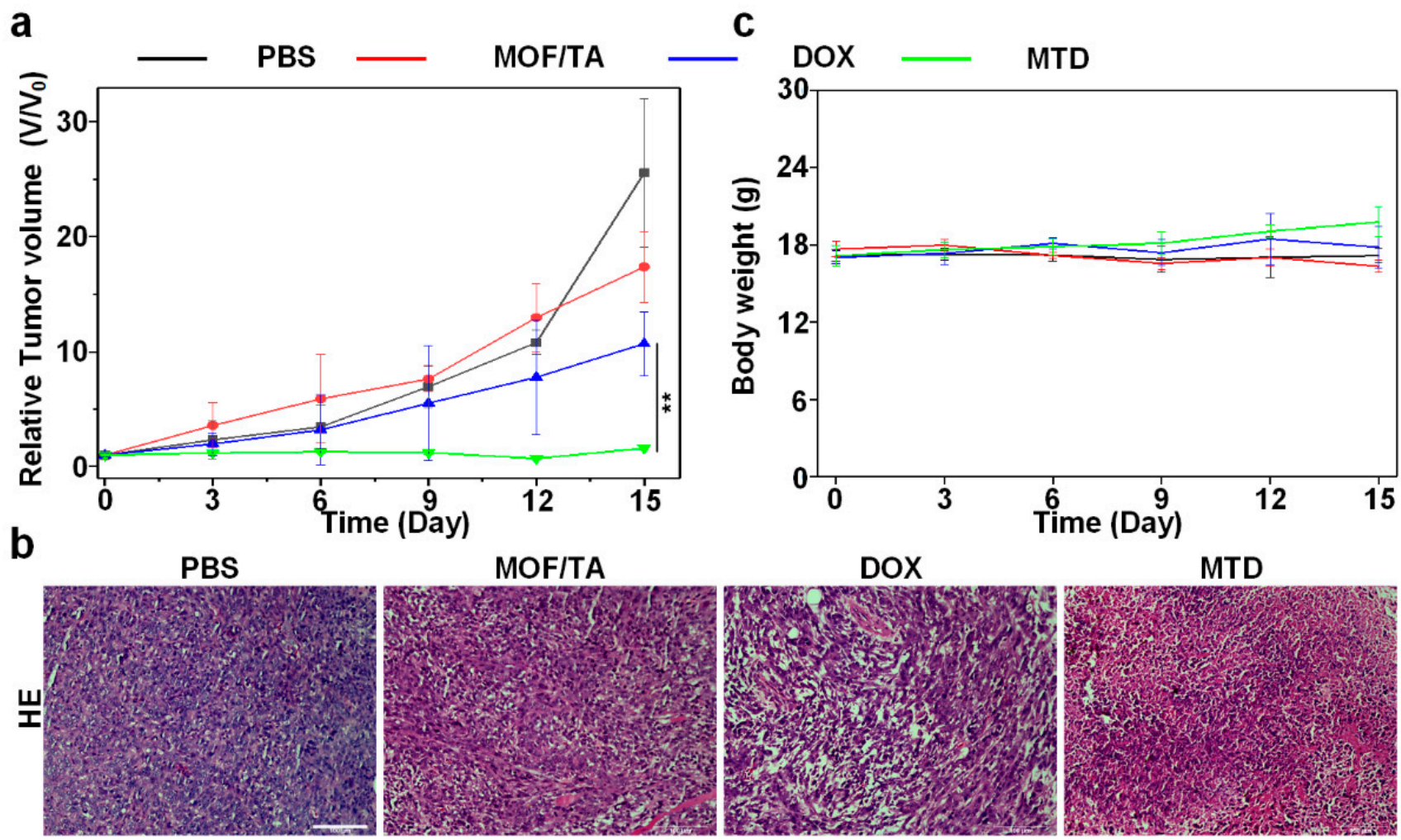

Figure 5. In vivo antitumor effects of MTD: (a) relative tumor volume of mice after different treatments; (b) H\&E analysis of mice tumors collected from different groups. Scale bar, $100 \mu \mathrm{m}$; (c) body weight of tumor-bearing mice during the treatment period. Data are represented as the arithmetic mean $\pm \mathrm{SD}$, and one-way ANOVA followed by Dunnett's test were performed for statistical analysis $\left({ }^{* *} p<0.01\right)$.

\section{Discussion}

Currently, two drug delivery nanosystems including liposomes and albumin nanoplatforms had already been approved by the FDA for clinical application [30]. However, the drug delivery to the tumor site relied considerably on the enhanced permeability and retention (EPR) effect, which was due to the defective blood vasculature of tumor tissues, poor lymphatic drainage, and increased vessel permeability [31]. It was only considered as a passive targeting strategy for drug delivery. In this study, although MTD could enhance the effective concentration of drugs at the tumor site by responsive release, it showed poor passive targeting and was easily captured by the reticuloendothelial system, while the chemical bonds on the surface of nanoparticles can be used to link with small molecules such as HA and anti-CD47 to bind receptors that are highly expressed on the surface of tumor cells to achieve active targeting of tumors. [32,33] Therefore, the targeting properties of nanodrugs would be further improved by surface modification of specific targeted molecules. In addition, the $\bullet \mathrm{OH}$ production performance was also affected by the limited residence time of nanodrugs in the tumor site. Although the $\bullet \mathrm{OH}$ was highly cytotoxic, the short duration is an obstacle to further improving the therapeutic efficacy of tumors. Surprisingly, the strategies of delicately designed nanoparticles may help to solve these difficulties. A previous study shows that, due to their small size, nanoparticles self-aggregate in a tumor microenvironment with high levels of GSH, thus enhancing tumor retention and accumulation of the nanoparticles [34]. It has also widely been reported that the mechanism by which nanoparticles degrade within the tumor microenvironment accompanies the release of the loaded catalytic enzymes, such as poly(ethylene glycol)- 
modified glucose oxidase (GOx), to continuously generate $\bullet \mathrm{OH}$ and enhance the killing effect of tumor cells $[35,36]$. In addition, the $\bullet \mathrm{OH}$ produced by the Fenton reaction between $\mathrm{H}_{2} \mathrm{O}_{2}$ and $\mathrm{Fe}^{3+} / \mathrm{Fe}^{2+}$ can initiate ferroptosis to enhance the killing effect [37]. Recently, immunotherapy, as an emerging strategy in tumor therapy, was expected to specifically inhibit tumors in the long term [38]. To date, numerous immunotherapeutic agents have been approved by FDA including checkpoint inhibitor drugs for targeting the PD-1/PDL1 axis and cytotoxic T-lymphocyte-associated antigen 4 (CTLA-4) [39]. Accumulating lines of evidence have also suggested chemotherapy combined with immune checkpoint inhibitors would enhance antitumor effects in tumor therapy [40,41]. • OH could trigger immunogenic cell death (ICD) and initiate a potentiated antitumor immune response, as reported in $[42,43]$. In previous research, we have verified that the $\bullet \mathrm{OH}$ nanogenerator enhances the antitumor immune response by inducing ICD in combination therapy with the PD-L1 blockade, efficiently inhibiting tumor growth [21]. Therefore, the combination of immunotherapy represented by immune checkpoint blockers (ICBs) with the nanodrugs mediated chemotherapy could be expected to achieve synergistic enhancement and even long-term antitumor effects.

\section{Conclusions}

In summary, we successfully prepared a $\mathrm{pH}$-responsive, iron-based nanoparticle (MTD), which contributes to enhancing the chemotherapeutic effect and reducing the side effects significantly. MTD increased the effective concentration of DOX at the tumor site and elevated the intracellular $\mathrm{H}_{2} \mathrm{O}_{2}$ concentration based on the characteristics of acidic responsive release and the dual functions of DOX. Accordingly, MTD demonstrated the best therapeutic effect in the 4T1 tumor model, with the highest inhibitory rate of $93.728 \%$, due to the chemotherapeutic effect and property of persistently producing $\bullet \mathrm{OH}$. Taken together, the drug-loaded, iron-rich MOF nanoparticles are promising to serve as activatable nanodrugs for reducing the toxic side effects of chemotherapy and improving the efficacy of tumor chemotherapy.

Author Contributions: L.W., W.R.C. and C.L. put forward the idea and designed the experiment; L.L., Y.Z. and H.L. conducted the experiment; L.W., J.S. and C.L. contributed most to the data analyses and wrote the manuscript; L.L., H.L. and Y.Z. contributed to organizing the data and writing the figure conception of the study; S.Y., Y.M. and Z.W. helped perform the analysis with constructive discussions. All authors have read and agreed to the published version of the manuscript.

Funding: This research was funded by the National Natural Science Foundation of China (61805049), the Guangdong Basic and Applied Basic Research Foundation (2020A1515011101, 2021A1515011703, 2020A1515010543), the Guangxi Natural Science Foundation (2020GXNSFBA297123), the Basic Ability Enhancement Program for Young and Middle-aged Teachers of Guangxi (20180071), and the Innovation Project of Guangxi Graduate Education (20210104195550).

Institutional Review Board Statement: The study was conducted in accordance with the Declaration of Helsinki, and approved by the Animal Research Ethics Committee of Guangxi University (protocol code GXU-2020-028 and date of approval 7 April 2020).

Informed Consent Statement: Not applicable.

Acknowledgments: We would like to acknowledge the Open Fund of MOE Key Laboratory of Laser Life Science and Institute of Laser Life Science.

Conflicts of Interest: The authors declare no conflict of interest.

\section{References}

1. Sung, H.; Ferlay, J.; Siegel, R.L.; Laversanne, M.; Soerjomataram, I.; Jemal, A.; Bray, F. Global Cancer Statistics 2020: GLOBOCAN Estimates of Incidence and Mortality Worldwide for 36 Cancers in 185 Countries. CA Cancer J. Clin. 2021, 71, 209-249. [CrossRef] [PubMed]

2. Bayon-Cordero, L.; Alkorta, I.; Arana, L. Application of Solid Lipid Nanoparticles to Improve the Efficiency of Anticancer Drugs. Nanomaterials 2019, 9, 474. [CrossRef] [PubMed] 
3. Zhou, L.; Wang, H.; Li, Y. Stimuli-Responsive Nanomedicines for Overcoming Cancer Multidrug Resistance. Theranostics 2018, 8, 1059-1074. [CrossRef] [PubMed]

4. $\quad$ Feng, C.; Rui, M.; Shen, H.; Xin, Y.; Zhang, J.; Li, J.; Yue, L.; Lai, W.; Xu, X. Tumor-specific delivery of doxorubicin through conjugation of $\mathrm{pH}$-responsive peptide for overcoming drug resistance in cancer. Int. J. Pharm. 2017, 528, 322-333. [CrossRef] [PubMed]

5. Shen, W.; Liu, W.; Yang, H.; Zhang, P.; Xiao, C.; Chen, X. A glutathione-responsive sulfur dioxide polymer prodrug as a nanocarrier for combating drug-resistance in cancer chemotherapy. Biomaterials 2018, 178, 706-719. [CrossRef] [PubMed]

6. Zang, Y.; Wei, Y.; Shi, Y.; Chen, Q.; Xing, D. Chemo/Photoacoustic Dual Therapy with mRNA-Triggered DOX Release and Photoinduced Shockwave Based on a DNA-Gold Nanoplatform. Small 2016, 12, 756-769. [CrossRef]

7. Choi, K.M.; Kwon, I.C.; Ahn, H.J. Self-assembled amphiphilic DNA-cholesterol/DNA-peptide hybrid duplexes with liposome-like structure for doxorubicin delivery. Biomaterials 2013, 34, 4183-4190. [CrossRef]

8. Kanwal, U.; Irfan Bukhari, N.; Ovais, M.; Abass, N.; Hussain, K.; Raza, A. Advances in nano-delivery systems for doxorubicin: An updated insight. J. Drug Target. 2018, 26, 296-310. [CrossRef]

9. Qiu, M.; Sun, H.; Meng, F.; Cheng, R.; Zhang, J.; Deng, C.; Zhong, Z. Lipopepsomes: A novel and robust family of nano-vesicles capable of highly efficient encapsulation and tumor-targeted delivery of doxorubicin hydrochloride in vivo. J. Control. Release 2018, 272, 107-113. [CrossRef]

10. Harris, L.; Batist, G.; Belt, R.; Rovira, D.; Navari, R.; Azarnia, N.; Welles, L.; Winer, E.; Group, T.D.S. Liposome-encapsulated doxorubicin compared with conventional doxorubicin in a randomized multicenter trial as first-line therapy of metastatic breast carcinoma. Cancer 2002, 94, 25-36. [CrossRef]

11. Hofheinz, R.D.; Gnad-Vogt, S.U.; Beyer, U.; Hochhaus, A. Liposomal encapsulated anti-cancer drugs. Anticancer Drugs 2005, 16, 691-707. [CrossRef] [PubMed]

12. Ran, M.; Zhen, G. Tumor microenvironment and intracellular signal-activated nanomaterials for anticancer drug delivery. Mater. Today 2015, 19, 274-283. [CrossRef]

13. Gong, F.; Yang, N.; Wang, X.; Zhao, Q.; Cheng, L. Tumor microenvironment-responsive intelligent nanoplatforms for cancer theranostics. Nano Today 2020, 32, 100851. [CrossRef]

14. Li, R.; Xie, Y. Nanodrug delivery systems for targeting the endogenous tumor microenvironment and simultaneously overcoming multidrug resistance properties. J. Control. Release 2017, 251, 49-67. [CrossRef]

15. Estrella, V.; Chen, T.; Lloyd, M.; Wojtkowiak, J.; Cornnell, H.H.; Ibrahim-Hashim, A.; Bailey, K.; Balagurunathan, Y.; Rothberg, J.M.; Sloane, B.F.; et al. Acidity generated by the tumor microenvironment drives local invasion. Cancer Res. 2013, 73, $1524-1535$. [CrossRef]

16. Qiu, J.; Xia, Y. Killing cancer cells by rupturing their lysosomes. Nat. Nanotechnol. 2020, 15, 252-253. [CrossRef]

17. Horcajada, P.; Serre, C.; Vallet-Regí, M.; Sebban, M.; Taulelle, F.; Férey, G. Metal-Organic Frameworks as Efficient Materials for Drug Delivery. Angew. Chem. Int. Ed. 2006, 118, 6120-6124. [CrossRef]

18. Gao, S.; Han, Y.; Fan, M. Metal-organic framework-based nanocatalytic medicine for chemodynamic therapy. Sci. China Mater. 2020, 63, 2429-2434. [CrossRef]

19. Wu, M.X.; Yang, Y.W. Metal-Organic Framework (MOF)-Based Drug/Cargo Delivery and Cancer Therapy. Adv. Mater. 2017, 29, 1606134. [CrossRef]

20. Wang, X.G.; Dong, Z.Y.; Cheng, H.; Wan, S.S.; Chen, W.H.; Zou, M.Z.; Huo, J.W.; Deng, H.X.; Zhang, X.Z. A multifunctional metal-organic framework based tumor targeting drug delivery system for cancer therapy. Nanoscale 2015, 7, 16061-16070. [CrossRef]

21. Liang, L.; Wen, L.; Weng, Y.; Song, J.; Li, H.; Zhang, Y.; He, X.; Zhao, W.; Zhan, M.; Li, Y. Homologous-Targeted and Tumor Microenvironment-Activated Hydroxyl Radical Nanogenerator for Enhanced Chemoimmunotherapy of Non-Small Cell Lung Cancer. Chem. Eng. J. 2021, 425, 131451. [CrossRef]

22. Mizutani, H.; Tada-Oikawa, S.; Hiraku, Y.; Kojima, M.; Kawanishi, S. Mechanism of apoptosis induced by doxorubicin through the generation of hydrogen peroxide. Life Sci. 2005, 76, 1439-1453. [CrossRef] [PubMed]

23. Deng, S.; Kruger, A.; Kleschyov, A.L.; Kalinowski, L.; Daiber, A.; Wojnowski, L. Gp91phox-containing NAD(P)H oxidase increases superoxide formation by doxorubicin and NADPH. Free Radic. Biol. Med. 2007, 42, 466-473. [CrossRef] [PubMed]

24. Taylor-Pashow, K.M.; Della Rocca, J.; Xie, Z.; Tran, S.; Lin, W. Postsynthetic modifications of iron-carboxylate nanoscale metalorganic frameworks for imaging and drug delivery. J. Am. Chem. Soc. 2009, 131, 14261-14263. [CrossRef] [PubMed]

25. Guo, S.; Sun, D.; Ni, D.; Yu, M.; Qian, K.; Zhang, W.; Yang, Y.; Song, S.; Li, Y.; Xi, Z. Smart Tumor Microenvironment-Responsive Nanotheranostic Agent for Effective Cancer Therapy. Adv. Funct. Mater. 2020, 30, 202000486. [CrossRef]

26. Zheng, Z.; Chen, Q.; Dai, R.; Jia, Z.; Yang, C.; Peng, X.; Zhang, R. A continuous stimuli-responsive system for NIR-II fluorescence/photoacoustic imaging guided photothermal/gas synergistic therapy. Nanoscale 2020, 12, 11562-11572. [CrossRef] [PubMed]

27. Zhang, C.; Bu, W.; Ni, D. Synthesis of iron nanometallic glasses and their application in cancer therapy by a localized Fenton reaction. Angew. Chem. 2016, 128, 2141-2146. [CrossRef]

28. Haque, E.; Jun, J.W.; Jhung, S.H. Adsorptive removal of methyl orange and methylene blue from aqueous solution with a metal-organic framework material, iron terephthalate (MOF-235). J. Hazard. Mater. 2011, 185, 507-511. [CrossRef] 
29. Wagner, B.A.; Evig, C.B.; Reszka, K.J.; Buettner, G.R.; Burns, C.P. Doxorubicin increases intracellular hydrogen peroxide in PC3 prostate cancer cells. Arch. Biochem. Biophys. 2005, 440, 181-190. [CrossRef]

30. Naccache, R.; Rodriguez, E.M.; Bogdan, N.; Sanz-Rodriguez, F.; Cruz Mdel, C.; Fuente, A.J.; Vetrone, F.; Jaque, D.; Sole, J.G.; Capobianco, J.A. High resolution fluorescence imaging of cancers using lanthanide ion-doped upconverting nanocrystals. Cancers 2012, 4, 1067-1105. [CrossRef]

31. Bretin, L.; Pinon, A.; Bouramtane, S.; Ouk, C.; Richard, L.; Perrin, M.L.; Chaunavel, A.; Carrion, C.; Bregier, F.; Sol, V.; et al. Photodynamic Therapy Activity of New Porphyrin-Xylan-Coated Silica Nanoparticles in Human Colorectal Cancer. Cancers 2019, 11, 1474. [CrossRef] [PubMed]

32. Chen, Z.-X.; Liu, M.-D.; Zhang, M.-K.; Wang, S.-B.; Xu, L.; Li, C.-X.; Gao, F.; Xie, B.-R.; Zhong, Z.-L.; Zhang, X.-Z. Interfering with Lactate-Fueled Respiration for Enhanced Photodynamic Tumor Therapy by a Porphyrinic MOF Nanoplatform. Adv. Funct. Mater. 2018, 28, 1803498. [CrossRef]

33. Ni, K.; Luo, T.; Culbert, A.; Kaufmann, M.; Jiang, X.; Lin, W. Nanoscale metal-organic framework co-delivers TLR-7 agonists and anti-CD47 antibodies to modulate macrophages and orchestrate cancer immunotherapy. J. Am. Chem. Soc. 2020, 142, 12579-12584. [CrossRef] [PubMed]

34. Wang, Y.; Shi, L.; Ma, D.; Xu, S.; Wu, W.; Xu, L.; Panahandeh-Fard, M.; Zhu, X.; Wang, B.; Liu, B. Tumor-Activated and Metal-Organic Framework Assisted Self-Assembly of Organic Photosensitizers. ACS Nano 2020, 14, 13056-13068. [CrossRef]

35. Fu, L.; Wan, Y.; Qi, C.; He, J.; Li, C.; Yang, C.; Xu, H.; Lin, J.; Huang, P. Nanocatalytic theranostics with glutathione depletion and enhanced reactive oxygen species generation for efficient cancer therapy. Adv. Mater. 2021, 33, 2006892. [CrossRef]

36. Ao, M.; Yu, F.; Li, Y.; Zhong, M.; Tang, Y.; Yang, H.; Wu, X.; Zhuang, Y.; Wang, H.; Sun, X.; et al. Carrier-free nanoparticles of camptothecin prodrug for chemo-photothermal therapy: The making, in vitro and in vivo testing. J. Nanobiotechnol. 2021, 19, 1-15. [CrossRef]

37. Liang, C.; Zhang, X.; Yang, M.; Dong, X. Recent progress in ferroptosis inducers for cancer therapy. Adv. Mater. 2019, 31, 1904197. [CrossRef]

38. Mi, Y.; Hagan, C.T.t.; Vincent, B.G.; Wang, A.Z. Emerging Nano-/Microapproaches for Cancer Immunotherapy. Adv. Sci. (Weinh.) 2019, 6, 1801847. [CrossRef]

39. Souquet, P.-J.; Couraud, S. Immune checkpoint inhibitors: A game changer for metastatic non-small-cell lung cancer. Lancet Oncol. 2019, 20, 1334-1335. [CrossRef]

40. Rizvi, N.A.; Hellmann, M.D.; Brahmer, J.R.; Juergens, R.A.; Borghaei, H.; Gettinger, S.; Chow, L.Q.; Gerber, D.E.; Laurie, S.A.; Goldman, J.W.; et al. Nivolumab in Combination With Platinum-Based Doublet Chemotherapy for First-Line Treatment of Advanced Non-Small-Cell Lung Cancer. J. Clin. Oncol. 2016, 34, 2969-2979. [CrossRef]

41. Paz-Ares, L.; Luft, A.; Vicente, D.; Tafreshi, A.; Gumus, M.; Mazieres, J.; Hermes, B.; Cay Senler, F.; Csoszi, T.; Fulop, A.; et al Pembrolizumab plus Chemotherapy for Squamous Non-Small-Cell Lung Cancer. N. Engl. J. Med. 2018, 379, 2040-2051. [CrossRef] [PubMed]

42. Xu, C.; Yu, Y.; Sun, Y.; Kong, L.; Yang, C.; Hu, M.; Yang, T.; Zhang, J.; Hu, Q.; Zhang, Z. Transformable Nanoparticle-Enabled Synergistic Elicitation and Promotion of Immunogenic Cell Death for Triple-Negative Breast Cancer Immunotherapy. Adv. Funct. Mater. 2019, 29, 201905213. [CrossRef]

43. Ranji-Burachaloo, H.; Gurr, P.A.; Dunstan, D.E.; Qiao, G.G. Cancer Treatment through Nanoparticle-Facilitated Fenton Reaction. ACS Nano 2018, 12, 11819-11837. [CrossRef] [PubMed] 